\title{
Treatment of subacute thoracic spine fracture-dislocation by total vertebrectomy and spine shortening
}

\author{
Technical note
}

\author{
Alecio C. E. S. Barcelos, M.D., M.S., ${ }^{1}$ And Ricardo V. Botelho, M.D., Ph.D. ${ }^{2}$ \\ ${ }^{1}$ Hospital de Emergência e Trauma Senador Humberto Lucena, João Pessoa, Paraíba; and ${ }^{2}$ Hospital do \\ Servidor Público Estadual de São Paulo, Brazil
}

\begin{abstract}
Vertebral resection with spine shortening has been primarily reported for the treatment of demanding cases of nontraumatic disorders. Recently, this technique has been applied to the treatment of traumatic disorders. The current treatment of vertebral fracture-dislocation when there is partial or total telescoping of the involved vertebrae is a combined anterior-posterior approach with corpectomy, anterior support implant, and further posterior instrumentation. These procedures usually require 2 surgical teams, involve longer operating times and greater risk of surgical complications related to the anterior approach, and commonly entail longer postoperative care before discharge. The authors report on 2 patients with high thoracic fracture-dislocations with telescoping (T-2 and T-4) who were treated in the subacute phase with total spondylectomy (T-3 and T-5, respectively) and spine shortening by using only a posterior approach. Complete recovery of the sagittal balance was achieved with this technique and the postoperative periods were clinically uneventful. One patient presented with asymptomatic hemothorax that did not require drainage. In paraplegic patients with anterior thoracic dislocation fractures in which one vertebral body blocks the reduction of the other, total spondylectomy and spine shortening seem to be a reasonably safe and effective technique. (http://thejns.org/doi/abs/10.3171/2012.10.SPINE12582)
\end{abstract}

\section{KEY Words - spine shortening - spondylectomy - vertebrectomy • spine fracture-dislocation $\quad \bullet \quad$ trauma}

$\mathrm{V}$ ERTEBRAL resection with spine shortening has been primarily reported for the treatment of demanding cases of nontraumatic disorders. It was first described in 1922 for the treatment of scoliosis through the posterior approach alone. ${ }^{15}$ Since then, this technique has been used in the management of congenital, 7,21,27,28 tumoral,,$^{17,29}$ infectious,${ }^{23,32,34}$ deformity, ${ }^{2-4,30,31}$ degenerative, $, 10,13$ and (recently) traumatic disorders. ${ }^{1,22}$

The current technique for vertebral fracture-dislocation when there is partial or total telescoping of the involved vertebrae is a combined anterior-posterior approach with corpectomy, anterior support implant, and further posterior instrumentation..$^{24,36}$ These procedures usually require 2 surgical teams, involve longer operating times and greater risk of surgical complications related to

Abbreviations used in this paper: ASIA = American Spinal Injury Association; SCI = spinal cord injury; VB = vertebral body. the anterior approach, and commonly entail longer postoperative care before discharge.

We report on 2 patients with high thoracic fracturedislocations with telescoping (T-2 and T-4) (Figs. 1A, 1B, and 2 left) who were treated in the subacute phase with total spondylectomy and spine shortening by using only a posterior approach.

\section{Methods}

Both patients were young adults who were victims of motor vehicle accidents and were paraplegic (ASIA Grade A) due to high thoracic spine translational fractures (Table 1).

\section{Surgical Technique}

Both operations were performed by the same surgeon (A.B.) using the same method (Fig. 3). 

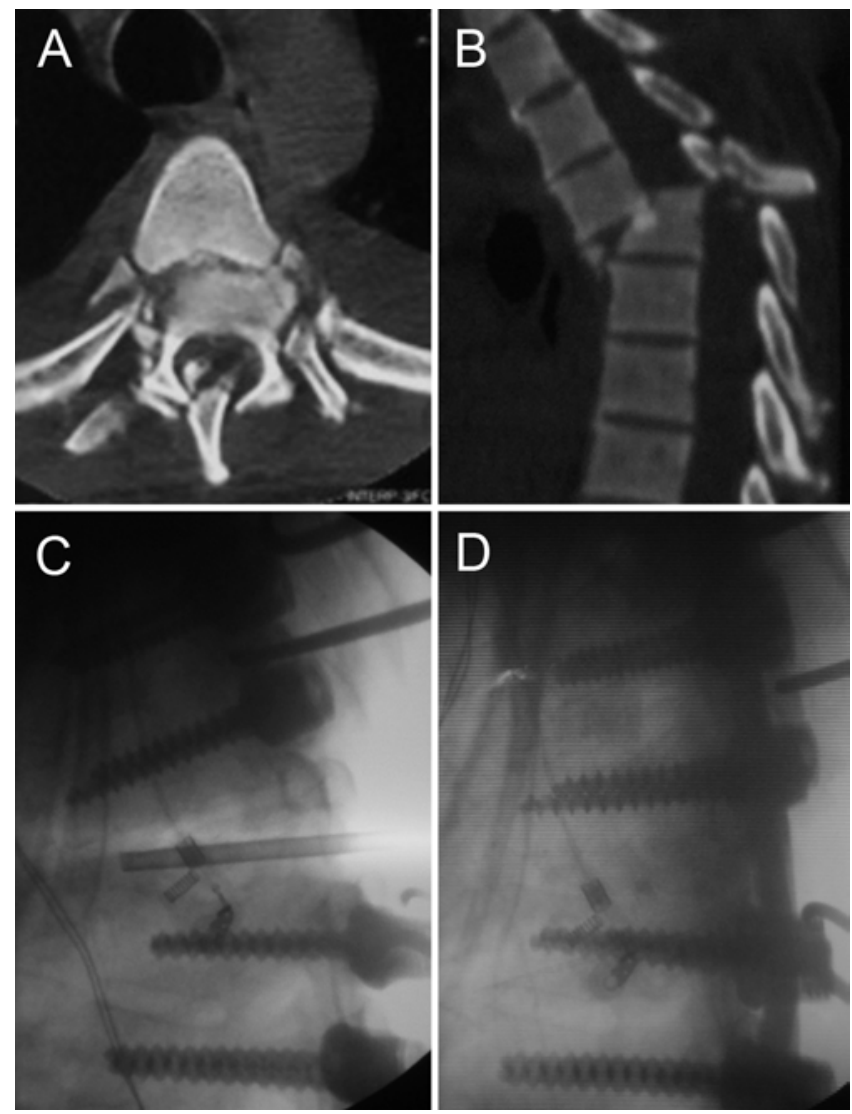

FIG. 1. Case 2. This 37-year-old man presented with T-4 fracturedislocation after a motorcycle accident. A and B: Preoperative CT scans showing the fracture-dislocation and anterior telescoping of T-4 over T-5. A T-5 vertebrectomy and spine shortening procedure were done 8 weeks after trauma. $\mathbf{C}$ and $\mathbf{D}$ : Intraoperative radiographic studies. After vertebrectomy, a partial reduction of the deformity was already seen $(C)$. After rods and caps were inserted and tightened, the reduction was fully accomplished and the sagittal balance restored (D).

Positioning. After induction of general anesthesia, the patient was placed prone and secured appropriately to the bed, so that the surgeon could safely rotate it slightly to the contralateral side when necessary.

Exposure. Through a midline incision, the vertebral posterior arches to be instrumented were exposed. The anterior dislocation fracture was evident. In both cases, posterior arch fractures were present (Fig. 3A and B). The paraspinal muscles were dissected subperiosteally from the spinous processes to the tips of the transverse processes.

Instrumentation. The pedicle screws were inserted 2 or 3 levels above and 2 levels below the lesion under
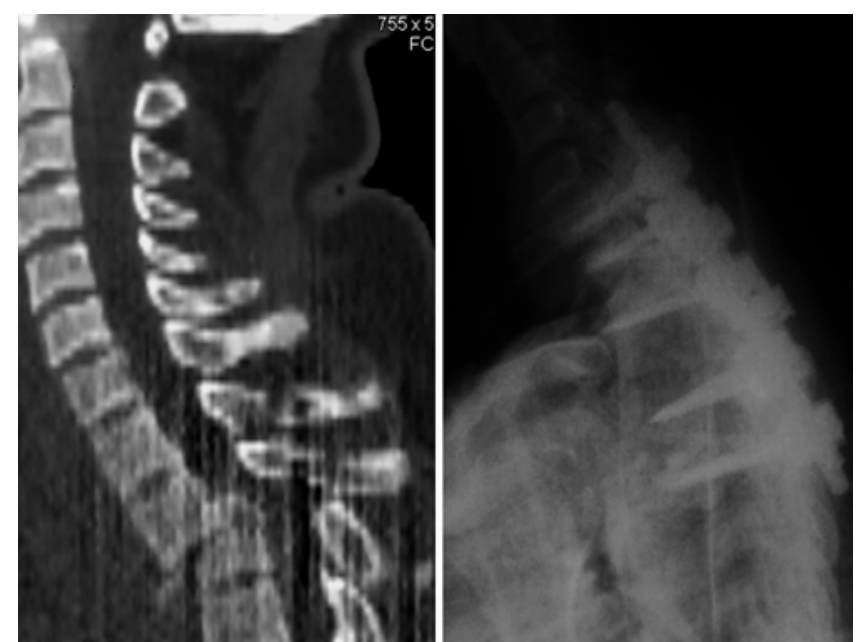

FIG. 2. Case 1. This 31-year-old woman presented with a T-2 fracturedislocation after a car accident. Left: Preoperative CT scan showing the fracture-dislocation and telescoping of T-2 in front of T-3. Right: Radiograph obtained after 3 months showing maintenance of dorsal spine alignment.

fluoroscopy guidance. In the T2-3 fracture (Case 1), C-7 instrumentation was performed to include the cervicothoracic junction (Fig. 3C).

Vertebrectomy. First, the spinous processes and laminae of the upper and lower fractured vertebrae were resected (T-2 and T-3 in Case 1, and T-4 and T-5 in Case 2). The spinous process of $\mathrm{T}-1$ in Case 1 and $\mathrm{T}-3$ in Case 2 were also resected to expose the immediately inferior posterior arch (Fig. 3B). In both cases, the dura mater was injured and surrounded by dense fibrous tissue. No CSF leak was observed. No attempt to remove this fibrous tissue was made, to prevent further complications such as CSF leakage.

Second, the pedicles and transverse processes of the lower vertebra were resected (T-3 in Case 1 and T-5 in Case 2). At this moment, the upper and lower roots were exposed bilaterally. In both cases, no rib resection was necessary. Then, the corpectomy of the inferior vertebra was accomplished in piecemeal fashion by using the eggshell technique. Using the high-speed drill, the central portion of the VB was removed (Fig. 3D and E). With use of curettes and impacters, the dorsal shell of the VB and the superior and inferior endplates were fractured into the defect and removed. The lateral wall of the VB was removed using the high-speed drill and rongeurs. Fluoroscopy was used to help define the limits of the VB resection. The underlying discs were completely removed. At that time, traction over the cranial and caudal spinous processes revealed unlocking of the luxation. After the

TABLE 1: Clinical data in 2 patients with VB fracture-dislocation*

\begin{tabular}{ccccccc}
\hline Case No. & Age (yrs), Sex & Mechanism of Trauma & Fx Level & AO Fx Classification & ASIA Grade & Neuro Level \\
\hline 1 & $31, \mathrm{~F}$ & car accident & T-2 & C3.1 + A1.2.1 & A & T-2 \\
2 & $37, \mathrm{M}$ & motorcycle accident & T-4 & C3.1 + A1.2.1 & A & T-4 \\
\hline
\end{tabular}

${ }^{*} \mathrm{Fx}=$ fracture; Neuro = neurological. 
corpectomy, the inferior endplate of the upper VB and the superior endplate of the lower VB were curetted until cancellous bone was exposed.

Reduction. After vertebrectomy, a partial reduction of the deformity was already noticed (Figs. 1C and 3F). At this time, one of the surgeons exited the surgical field to reposition the patient with larger thoracic pads to pro- mote an additional postural reduction. The rods were fixed first to the inferior pedicles and then to the superior pedicles with the use of the persuader. After rods and caps were inserted and tightened the reduction was fully accomplished, with an excellent realignment of the dorsal spine (Figs. 3G, 3H, and 1D). Autologous local bone graft was used to fill in the gap between the upper and lower VBs. The transverse processes and/or laminae of the in-

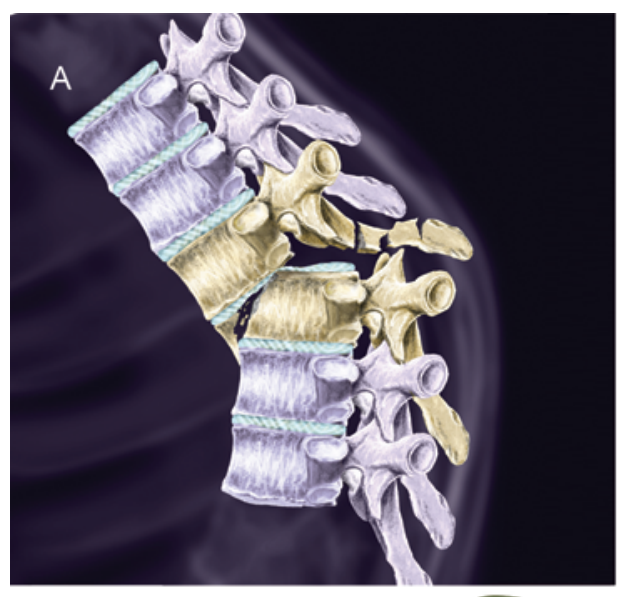

B

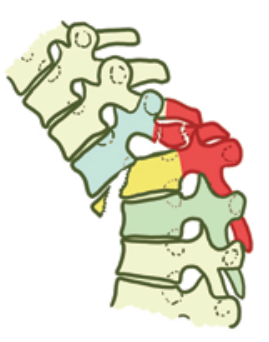

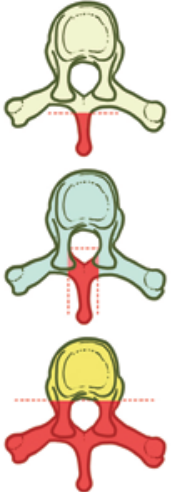

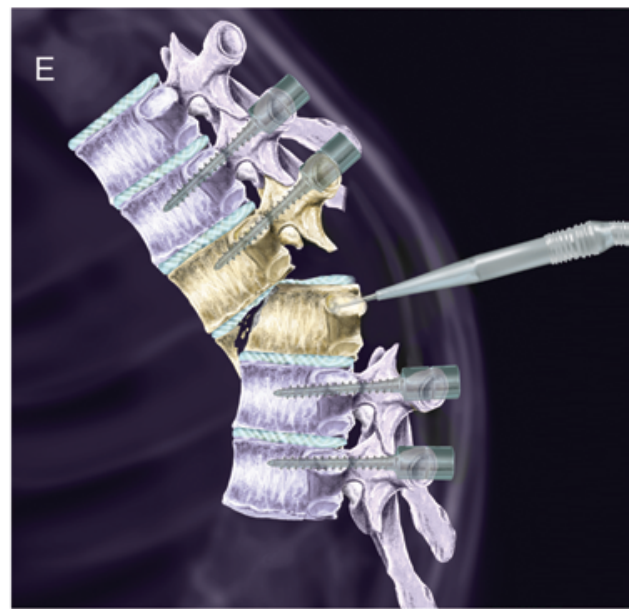

$\mathrm{F}$

G
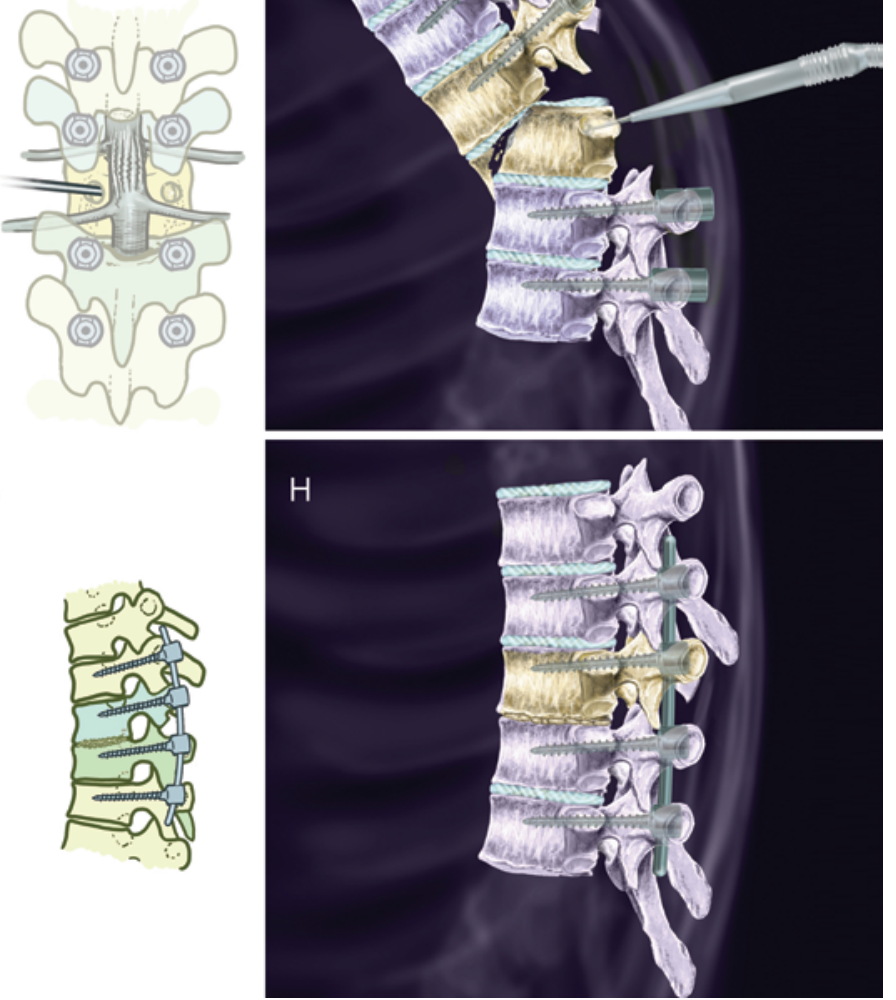

FIG. 3. Schematic illustrations of total spondylectomy and spine shortening. A: A 3D image of the thoracic spine fracturedislocation. B: The posterior elements resected (colored red) and the corpectomy of the inferior vertebra (colored yellow). C: First the pedicle screws were inserted and then the posterior elements were resected. D and E: Upper and lower roots were exposed bilaterally and the corpectomy of the inferior vertebra was performed. F: After vertebrectomy, a partial reduction of the deformity was already noticed. G: After rods and caps were inserted and tightened, the reduction was fully accomplished. $\quad \mathbf{H}$ : Complete fracture reduction. 


\section{Treatment of subacute thoracic spine fracture-dislocation}

strumented vertebrae were decorticated and the intervals between them were packed with local bone graft (from the resected posterior arches and VB) and allograft (hydroxyapatite).

Wound Closure. The wound was closed in layers and a closed suction drain was left in place for 48 hours.

\section{Results}

Total vertebrectomy was done at T-3 (Case 1) and T-5 (Case 2). The operating times were 360 minutes (Case 1) and 405 minutes (Case 2). Both patients received packed red blood cell transfusion (Table 2). Prophylactic antibiotics were given for 48 hours. Although he was asymptomatic, the patient in Case 2 presented with bilateral hemothorax that did not require drainage. The patients' rehabilitation program began 1 day after surgery. Neither patient used spinal braces postoperatively. The patients went home on the 3 rd and 7th postoperative day, respectively.

The immediate postoperative image showed excellent realignment of the dorsal spine (Fig. 1D). The complete reduction achieved after vertebrectomy and spine shortening followed by posterior fusion with pedicle screws resulted in restored coronal and sagittal balances. Follow-up images showed an excellent reduction and fusion in both cases without loss of correction (Figs. 4A and 2 right). When there was no proximal rib resection at the level of the vertebrectomy, the intercostal spaces between the 3 ribs adjacent to the upper and lower vertebrae were narrowed, although they did not touch each other. This finding did not result in intercostal neuralgia postoperatively (Fig. 4B and C). There was no implant failure. At latest follow-up, both patients were neurologically stable (ASIA Grade A) and their daily functional abilities were progressively improving. There was no spine-related pain. The local deformity was assessed using the Cobb method, from the upper endplate of the vertebra above the deformity to the inferior endplate of the vertebra below it (Table 3).

\section{Discussion}

The major characteristics of thoracolumbar injuries that influence the surgical decision are the injury's morphological features, the patient's neurological status, and posterior ligament integrity. ${ }^{35}$ Anterior and posterior element injuries with rotation represent the most harmful traumas of the thoracic spine, and are associated with the highest rate of neurological deficit. Neural injury is caused by bone fragments and/or encroachment of the spinal canal resulting from translational displacement. It is rare for these dislocations not to cause neurological deficits. ${ }^{26}$ Rotational shear injuries with slice fracture (C3.1; and not oblique fracture) represented 3 of 1212 patients in the series by Magerl et al. ${ }^{16}$ According to Holdsworth, ${ }^{11}$ these fractures are "by far the most unstable of all injuries of the spine." Magerl considered slice fractures to be more dangerous than rotational shear oblique fractures with regard to spinal cord compression, because of the shear on the horizontal plane..$^{16}$

The primary goals of surgical treatment of thoracic fracture-dislocation with complete spinal cord transection are reduction of the deformity and rigid spine stabilization with fusion. According to Vaccaro et al., ${ }^{35}$ patients are best treated surgically via a posterior approach in the presence of distraction, disrupted posterior ligamentous complex in anterior translation, and complete SCI. However, to restore the anterior weight support and the spine sagittal balance it is necessary to reduce the anterior dislocation prior to posterior instrumentation. In cases of vertebral fracture-dislocation, some authors recommend a combined anterior-posterior approach with corpectomy, anterior support implant, and further posterior instrumentation. ${ }^{5,18,24,36}$ The posterolateral approaches such as lateral extracavitary and costotransversectomy also allow surgeons to access the ventral thoracic spine for a wide range of spinal disorders including tumor, degeneration, infection, and trauma. ${ }^{14,33}$ As stated in his comment on a paper by Resnick and Benzel, ${ }^{25}$ Sonntag thought that these approaches are appropriate for an injury such as a fracture subluxation of the thoracic and thoracolumbar spine, for which both anterior and posterior approaches may be indicated. Nevertheless, a systematic review that included 774 patients showed a mean complication rate of $39 \%, 17 \%$, and $15 \%$ for thoracotomy, lateral extracavitary approach, and costotransversectomy, respectively. ${ }^{14}$ For the anterior approach the main complications are hemothorax, chylothorax, pneumonia, dural tear, vessel injury, postoperative ileus, infection, intercostal neuralgia, postthoracotomy pain, and deep venous thrombosis. ${ }^{6,8,38}$ Even via a posterior midline approach, the proximal ribs can be resected if needed. The surgical approach is a tool used to achieve a predetermined operative objective. The rate of complications is also related to the surgeon's selection criteria, timing, judgment, operative objective, and technical performance. ${ }^{18}$

Total vertebrectomy and spine shortening via a posterior approach have been used in the management of different nontraumatic disorders. ${ }^{2-4,6,9,10,13,15,17,21,23,27-32,34}$ Despite the avoidance of an anterior approach, these are also demanding procedures that may be complicated with hematomas, infections, hemopneumothorax, fixation failures, and also neurological deficits. The latter have been attributed to the excessive straightening of the spinal cord in the concave side after correction, ${ }^{30,31}$ or to dural buckling with ischemic results. ${ }^{4}$

TABLE 2: Surgical data in 2 patients with VB fracture-dislocation*

\begin{tabular}{cccccc}
\hline Case No. & Fx Level & Fusion Level & Surgical Delay Posttrauma $(w k s)$ & Op Time (mins) & RBC Transfusion (ml) \\
\hline 1 & T-2 & C7-T5 & 15 & 360 & 986 \\
2 & T-4 & T3-7 & 8 & 405 & 630 \\
\hline
\end{tabular}

* $\mathrm{RBC}=$ red blood cell. 
A. C. E. S. Barcelos and R. V. Botelho
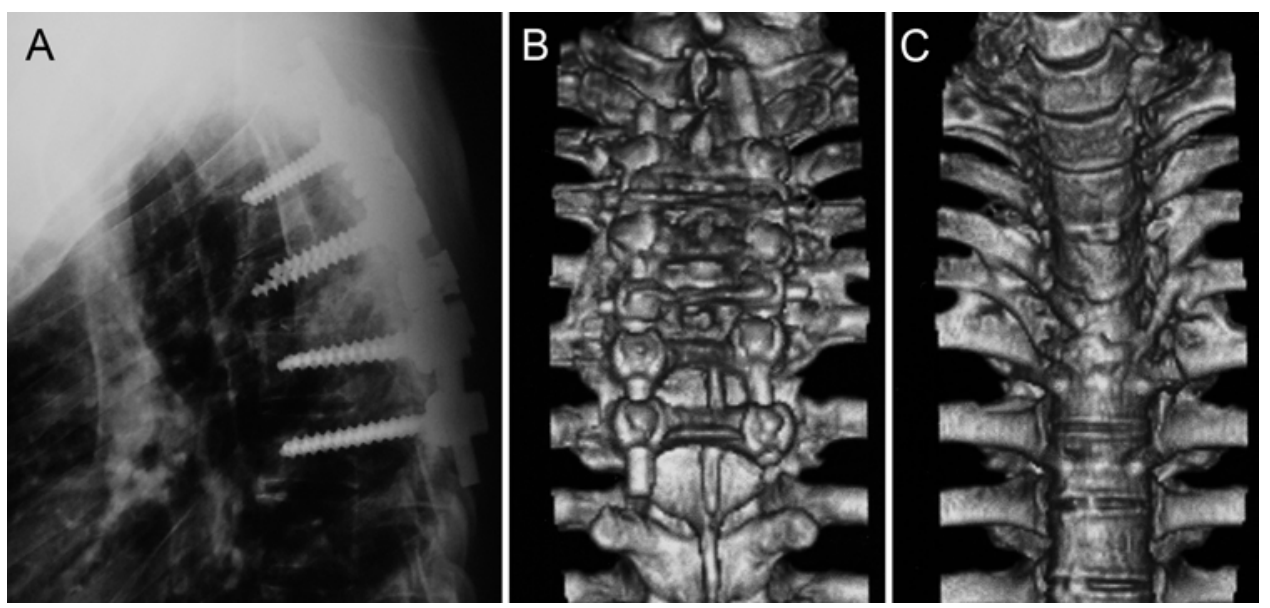

FIG. 4. Case 2. Follow-up images obtained 20 months after surgery. Radiograph (A) shows T4-6 interbody fusion and maintenance of the reduction. The 3D CT images show posterolateral fusion of the instrumented vertebrae. Note the narrowing of the 4th and 5th intercostal spaces (B and C).

An experimental study in swine assessed the SCI after spine shortening. The authors monitored spinal cord function and blood flow simultaneously with the use of transcranial motor evoked potentials and laser Doppler flowmetry, respectively. An SCI occurred when shortening was equivalent to the height of 1 vertebra at the thoracolumbar level, or higher than the mean segmental height of the entire thoracic and lumbar spine..$^{20}$ Therefore, we do not recommend total vertebrectomy and spine shortening in patients with incomplete SCIs. In these cases the combined anterior-posterior or posterolateral approaches followed by spinal cord decompression, restoration of the vertebral segment height with structural interbody graft or titanium surgical mesh filled with graft, and stabilization are preferred because they are rarely associated with neurological deterioration. ${ }^{5,14,25}$

There are few reports concerning total vertebrectomy and spine shortening in the treatment of traumatic injuries, all of them involving paraplegic patients. ${ }^{1,22}$ Although this technique provides decompression of the spinal canal and spine stabilization, this is essentially a mechanical surgery. In spite of the great efforts to date to improve neurological function after SCI, patients with complete lesions (ASIA Grade A), especially above T-9, are not expected to achieve functional recovery. ${ }^{8,37}$

Barberá ${ }^{1}$ reported the case of a young posttraumatic paraplegic patient (ASIA Grade A) with severe chronic (8 months) thoracolumbar (T12-L1 telescoped) kyphotic deformity that was corrected by a single-level spondylectomy with spine shortening; this was accomplished using a posterior approach. Obeid et al. ${ }^{22}$ reported total vertebrectomy and spine shortening for acute thoracic spine fracture dislocation. They described some advantages of this technique, such as a single approach (posterior) and the fact that the apposition of the adjacent healthy endplates permits an excellent reconstruction of the anterior spinal column and might provide an excellent interbody fusion rate. According to them, total vertebrectomy facilitated reduction and shortening of the spine, avoided traction on adjacent vascular elements, and seemed to be less traumatic for the adjacent structures. These authors considered it safer to perform long posterior instrumented fusion with at least 3 levels above and below the injury. Because spine shortening provided an excellent realignment without biomechanical stress and the preoperative images and intraoperative inspection suggested posterior ligamentous complex injury only at the level of dislocation, we applied posterior instrumentation only 2 levels above and below the injury in Case 2 (T4-5). In Case 1 (T2-3), C-7 was also instrumented to avoid stopping fusion immediately below the cervicothoracic junction.

During the surgical decision making, the choice for a total vertebrectomy and spine shortening must also consider the degree of the dislocation. If the anteroinferior edges of the adjacent vertebra's endplates (for example T-2 and T-3 in Case 1, and T-4 and T-5 in Case 2) are almost at the same horizontal plane, total vertebrectomy might allow full reduction, with a gap no larger than the height of the intervertebral disc space. This should be packed with cancellous bone. However, if a large interbody gap remains after the vertebrectomy and the reduction, resection of the proximal ribs and placement of a structural interbody graft might improve closure of the gap and provide anterior support to improve fusion and preserve the sagittal balance. ${ }^{12}$ In some fracture-dislocations, the resection of the injured disc and partial corpectomy of

TABLE 3: Follow-up data in 2 patients with VB fracture-dislocation

\begin{tabular}{|c|c|c|c|c|c|c|}
\hline \multirow[b]{2}{*}{ Case No. } & \multicolumn{3}{|c|}{ Kyphosis $\left({ }^{\circ}\right)$} & \multirow[b]{2}{*}{ Pain } & \multirow[b]{2}{*}{ ASIA Grade } & \multirow[b]{2}{*}{ Follow-Up (mos) } \\
\hline & Preop & Immediate Postop & Late Postop & & & \\
\hline 1 & 28 & 20 & 20 & no & $A$ & 3 \\
\hline 2 & 32 & 16 & 16 & no & $A$ & 20 \\
\hline
\end{tabular}


the inferior vertebra involved might be enough to allow reduction and superimposition of the adjacent vertebrae.

All preoperative images of T4-5, T6-7, and T9-10 dislocations presented by Obeid et al. ${ }^{22}$ showed traumatic hemothoraxes that might have been related to the spine fractures themselves or to other injuries not mentioned in the report. However, the postoperative period was uneventful. These patients all underwent operations during the acute phase. One of our patients (Case 2) had surgery in the 8th week posttrauma and experienced bilateral hemothoraxes postoperatively that did not require drainage. Probably the bleeding occurred from vessels in scar tissue that were stretched during the reduction. This fact does not seem to override the other benefits of this technique.

\section{Conclusions}

Thoracic spine dislocation results in some of the most difficult biomechanical conditions for internal fixation. The recovery of sagittal balance to a physiological alignment certainly minimizes the stress on the implants. Therefore it is of paramount importance to reduce the dislocation as much as possible to provide a rigid fixation and fusion. In paraplegic patients with anterior thoracic dislocation fractures where one VB blocks the reduction of the other, total spondylectomy and spine shortening seem to be a reasonably safe and effective technique.

\section{Disclosure}

The authors report no conflict of interest concerning the materials or methods used in this study or the findings specified in this paper.

Author contributions to the study and manuscript preparation include the following. Conception and design: Barcelos. Acquisition of data: Barcelos. Analysis and interpretation of data: Barcelos. Drafting the article: Barcelos. Critically revising the article: both authors. Reviewed submitted version of manuscript: both authors. Approved the final version of the manuscript on behalf of both authors: Barcelos.

\section{References}

1. Barberá J: T12-L1 telescoped chronic dislocation treated by en bloc one-piece spondylectomy and spine shortening. J Spinal Disord Tech 17:163-166, 2004

2. Boachie-Adjei O, Bradford DS: Vertebral column resection and arthrodesis for complex spinal deformities. J Spinal Disord 4:193-202, 1991

3. Bradford DS, Tribus CB: Vertebral column resection for the treatment of rigid coronal decompensation. Spine (Phila Pa 1976) 22:1590-1599, 1997

4. Bridwell KH: Decision making regarding Smith-Petersen vs. pedicle subtraction osteotomy vs. vertebral column resection for spinal deformity. Spine (Phila Pa 1976) 31 (19 Suppl):S171-S178, 2006

5. D'Aliberti G, Talamonti G, Villa F, Debernardi A, Sansalone CV, LaMaida A, et al: Anterior approach to thoracic and lumbar spine lesions: results in 145 consecutive cases. Clinical article. J Neurosurg Spine 9:466-482, 2008

6. Eckstein HB, Vora RM: Spinal osteotomy for severe kyphosis in children with myelomeningocele. J Bone Joint Surg Br 54: 328-333, 1972

7. Faciszewski T, Winter RB, Lonstein JE, Denis F, Johnson L: The surgical and medical perioperative complications of anterior spinal fusion surgery in the thoracic and lumbar spine in adults. A review of 1223 procedures. Spine (Phila Pa 1976) 20:1592-1599, 1995

8. Fehlings MG, Cadotte DW, Fehlings LN: A series of systematic reviews on the treatment of acute spinal cord injury: a foundation for best medical practice. J Neurotrauma 28:1329-1333, 2011

9. Gaines RW: L5 vertebrectomy for the surgical treatment of spondyloptosis: thirty cases in 25 years. Spine (Phila Pa 1976) 30 (6 Suppl):S66-S70, 2005

10. Gaines RW, Nichols WK: Treatment of spondyloptosis by two stage L5 vertebrectomy and reduction of L4 onto S1. Spine (Phila Pa 1976) 10:680-686, 1985

11. Holdsworth FW: Fractures, dislocations, and fracture-dislocations of the spine. J Bone Joint Surg Am 52:1534-1551, 1970

12. Kawahara N, Tomita K, Baba H, Kobayashi T, Fujita T, Murakami H: Closing-opening wedge osteotomy to correct angular kyphotic deformity by a single posterior approach. Spine (Phila Pa 1976) 26:391-402, 2001

13. Lehmer SM, Keppler L, Biscup RS, Enker P, Miller SD, Steffee AD: Posterior transvertebral osteotomy for adult thoracolumbar kyphosis. Spine (Phila Pa 1976) 19:2060-2067, 1994

14. Lubelski D, Abdullah KG, Steinmetz MP, Masters F, Benzel EC, Mroz TE, et al: Lateral extracavitary, costotransversectomy, and transthoracic thoracotomy approaches to the thoracic spine: review of techniques and complications. J Spinal Disord Tech [epub ahead of print], 2011

15. MacLennan A: Scoliosis. BMJ 2:865-866, 1922

16. Magerl F, Aebi M, Gertzbein SD, Harms J, Nazarian S: A comprehensive classification of thoracic and lumbar injuries. Eur Spine J 3:184-201, 1994

17. Magerl F, Coscia MF: Total posterior vertebrectomy of the thoracic or lumbar spine. Clin Orthop Relat Res 232:62-69, 1988

18. McCormick P: Lateral extracavitary approach for thoracic and thoracolumbar spine trauma: operative complications. Neurosurgery 43:796-803, 1998

19. McDonnell MF, Glassman SD, Dimar JR II, Puno RM, Johnson JR: Perioperative complications of anterior procedures on the spine. J Bone Joint Surg Am 78:839-847, 1996

20. Modi HN, Suh SW, Hong JY, Yang JH: The effects of spinal cord injury induced by shortening on motor evoked potentials and spinal cord blood flow: an experimental study in Swine. J Bone Joint Surg Am 93:1781-1789, 2011

21. Nolden MT, Sarwark JF, Vora A, Grayhack JJ: A kyphectomy technique with reduced perioperative morbidity for myelomeningocele kyphosis. Spine (Phila Pa 1976) 27:1807-1813, 2002

22. Obeid I, Guérin P, Gille O, Gangnet N, Aurouer N, Pointillart $\mathrm{V}$, et al: Total vertebrectomy and spine shortening in the management of acute thoracic spine fracture dislocation: technical note and report of 3 cases. J Spinal Disord Tech 24:340-345, 2011

23. Pappou IP, Papadopoulos EC, Swanson AN, Mermer MJ, Fantini GA, Urban MK, et al: Pott disease in the thoracolumbar spine with marked kyphosis and progressive paraplegia necessitating posterior vertebral column resection and anterior reconstruction with a cage. Spine (Phila Pa 1976) 31:E123E127, 2006

24. Patel A, Brown Z, Whang PG, Vaccaro AR: Thoracolumbar spine trauma. Oper Tech Orthop 17:190-198, 2007

25. Resnick DK, Benzel EC: Lateral extracavitary approach for thoracic and thoracolumbar spine trauma: operative complications. Neurosurgery 43:796-803, 1998

26. Shapiro S, Abel T, Rodgers RB: Traumatic thoracic spinal fracture dislocation with minimal or no cord injury. Report of four cases and review of the literature. J Neurosurg 96 (3 Suppl):333-337, 2002

27. Sharrard WJW: Spinal osteotomy for congenital kyphosis in myelomeningocele. J Bone Joint Surg Br 50:466-471, 1968 


\section{A. C. E. S. Barcelos and R. V. Botelho}

28. Sharrard WJW, Drennan JC: Osteotomy-excision of the spine for lumbar kyphosis in older children with myelomeningocele. J Bone Joint Surg Br 54:50-60, 1972

29. Shimizu K, Ido K, Fujio K, Tanaka K, Nakamura T: Total spondylectomy and spinal shortening for giant-cell tumour of spine. Lancet 348:342-348, 1996

30. Suk SI, Chung ER, Lee SM, Lee JH, Kim SS, Kim JH: Posterior vertebral column resection in fixed lumbosacral deformity. Spine (Phila Pa 1976) 30:E703-E710, 2005

31. Suk SI, Kim JH, Kim WJ, Lee SM, Chung ER, Nah KH: Posterior vertebral column resection for severe spinal deformities. Spine (Phila Pa 1976) 27:2374-2382, 2002

32. Sundararaj GD, Behera S, Ravi V, Venkatesh K, Cherian VM, Lee V: Role of posterior stabilisation in the management of tuberculosis of the dorsal and lumbar spine. J Bone Joint Surg Br 85:100-106, 2003

33. Sundararaj GD, Venkatesh K, Babu PN, Amritanand R: Extended posterior circumferential approach to thoracic and thoracolumbar spine. Oper Orthop Traumatol 21:323-334, 2009

34. Tuli SM: Treatment of neurological complications in tuberculosis of the spine. J Bone Joint Surg Am 51:680-692, 1969

35. Vaccaro AR, Lehman RA Jr, Hurlbert RJ, Anderson PA, Harris M, Hedlund R, et al: A new classification of thoracolumbar injuries: the importance of injury morphology, the integrity of the posterior ligamentous complex, and neurologic status. Spine (Phila Pa 1976) 30:2325-2333, 2005

36. Vaccaro AR, Lim MR, Hurlbert RJ, Lehman RA Jr, Harrop J, Fisher DC, et al: Surgical decision making for unstable thoracolumbar spine injuries: results of a consensus panel review by the Spine Trauma Study Group. J Spinal Disord Tech 19:1-10, 2006

37. Waters RL, Yakura JS, Adkins RH, Sie I: Recovery following complete paraplegia. Arch Phys Med Rehabil 73:784-789, 1992

38. Wiggins GC, Mirza S, Bellabarba C, West GA, Chapman JR, Shaffrey CI: Perioperative complications with costotransversectomy and anterior approaches to thoracic and thoracolumbar tumors. Neurosurg Focus 11(6):e4, 2001

Manuscript submitted June 8, 2012.

Accepted October 18, 2012.

Please include this information when citing this paper: published online November 23, 2012; DOI: 10.3171/2012.10.SPINE12582.

Address correspondence to: Alecio C. E. S. Barcelos, M.D., Rua Doutor João Franca, 242, 602 - Manaíra, João Pessoa-PB - Brazil, 58038190.email: aleciobarcelos_neuro@yahoo.com.br. 